\title{
3D reflection seismic imaging of the iron-oxide deposits in the Ludvika mining area (Sweden) using a focusing pre-stack depth migration approach
}

Felix Hloušek ${ }^{1}$, Michal Malinowski ${ }^{2,3}$, Lena Bräunig ${ }^{1}$, Stefan Buske ${ }^{1}$, Alireza Malehmir ${ }^{4}$, Magdalena

5 Markovic $^{4}$, Lukasz Sito $^{5}$, Paul Marsden ${ }^{6}$, Emma Bäckström ${ }^{6}$

${ }^{1}$ TU Bergakademie Freiberg, Freiberg, Germany

${ }^{2}$ Institute of Geophysics, Polish Academy of Sciences, Warsaw, Poland

${ }^{3}$ Geological Survey of Finland, Espoo, Finland

${ }^{4}$ Department of Earth Sciences, Uppsala University, Uppsala, Sweden

$10{ }^{5}$ Geopartner, Poland

${ }^{6}$ Nordic Iron Ore AB, Ludvika, Sweden

Correspondence to: Felix Hloušek (felix.hlousek@geophysik.tu-freiberg.de)

\begin{abstract}
.
We present the pre-stack depth imaging results for a case study of 3D reflection seismic exploration at the Blötberget iron-

oxide mining site belonging to the Bergslagen mineral district in central Sweden. The goal of this case study is to directly image the ore-bearing units and to map its possible extension down to greater depths than known from existing boreholes. Therefore, we applied a tailored pre-processing workflow as well as two different seismic imaging approaches, Kirchhoff prestack depth migration and Fresnel Volume Migration (FVM). Both imaging techniques deliver a well resolved 3D image of the deposit and its host rock, where the FVM image yields a significantly better image quality compared to the KPSDM image.
\end{abstract}

20 We were able to unravel distinct reflection horizons, which are linked to known mineralisation and provide insights on lateral and depth extent of the deposits beyond their known extension from borehole data. A comparison of the known mineralization and the image show a good agreement of the position and the shape of the imaged reflectors caused by the mineralization. Furthermore, the images show a reflector, which is interpreted to be a fault intersecting the mineralisation and which can be linked to the surface geology. The depth imaging results can serve as the basis for further investigations, drillings and followup mine planning at the Blötberget mining site.

\section{Introduction}

In the last decades the need for raw materials has increased worldwide. This increasing demand accounts also for the European Union. However, in contrast to this demand, current exploration and mining activities and the development of new mineral resources is still on a low level. Several mines were abandoned between the 60s and 80s of the last century, since mining in

30 Europe was too expensive and global prices were constantly falling. In recent years, the European Union follows the goal to reactivate activities related the exploration and production of critical minerals, with a special focus on the so-called critical 
https://doi.org/10.5194/se-2021-101

Preprint. Discussion started: 17 August 2021

(c) Author(s) 2021. CC BY 4.0 License.

\section{(c) (1)}

raw materials (e.g. Malehmir et al., 2012). In that context, a reliable and cost-effective exploration of such minerals is an important step in the early stage of the whole raw materials value chain. Therefore, the European Union supports several projects that focus on the improvement of this exploration stage, e.g. through the EU funded project Smart Exploration ${ }^{\mathrm{TM}}$, which has the primary goal to improve and to create new ways for mineral exploration using geophysical methods.

Seismic methods play an important role in the mineral exploration. They have the potential to allow for a high-resolution characterization of mineral deposits at depth. Especially, reflection seismic surveys can yield a structural image of potential deposits, their host rocks and other geological structures related to the understanding of their genesis such as faults and fracture systems. However, reflection seismic methods in mineral exploration are not yet as well established as in hydrocarbon exploration. Their application is often challenged by the corresponding hardrock environment causing strong scattering of the seismic wavefield as well as by complex 3D structures, since the geological units can show strongly varying strike and dip directions which may intersect each other. Furthermore, the expectable signal to noise ratio is rather low due to low impedance contrasts and strong scattering attenuation. Additionally, typical land seismic issues, such as irregular source and receiver

45 spacing, topographic effects and a strong near surface velocity gradients must be considered during seismic data processing. Although reflection seismics has the potential to produce high-resolution structural images of potential targets, its application for mineral exploration has been limited during the last decades and only lately starts to gain increased popularity (Malehmir et al., 2012). Several studies have shown the potential of 2D and 3D reflection seismic investigations for mineral exploration (e.g. Bellefleur et al., 2015; Cheraghi, Malehmir, and Bellefleur, 2012; Malehmir et al., 2012 and references therein; Urosevic,

50 Bhat, and Grochau, 2012; Milkereit, et al., 1996), but methodological improvements are still needed on the seismic imaging side especially in the case complex subsurface structures and in the case of irregular acquisition geometries, which are typical reflection seismic surveys in the European and Northern countries due to the environmental and accessibility issues.

The work presented in this paper has been performed as part of the Smart Exploration ${ }^{\mathrm{TM}}$ project and focuses on imaging mineral resources using reflection seismic methods with a special focus on pre-stack depth imaging techniques. We showcase

55 this approach for an investigation area located in the Bergslagen mining district in central Sweden (Figure 1). The deposit itself consists mainly of magnetite and hematite, which occurs in 30-50 m thick sheet-like bodies dipping towards the South-East to around $850 \mathrm{~m}$ depth (Maries et al., 2017; Malehmir et al., 2017). 2D reflection seismic profiles had been acquired already in 2015/2016 crossing the known mineralization perpendicular to its main strike direction. This data set was successfully processed using a standard time-domain processing and post-stack imaging workflow (Markovic et al., 2020) and Kirchhoff pre-stack depth migration (KPSDM) as well as focusing imaging approaches (Bräunig et al., 2019). The results of these 2D surveys show a clear image of the expected mineralization bodies and its surrounding structures at depth. The obtained seismic images show that the known mineralization is likely extending deeper than previously known from e.g. borehole investigations. The images also show internal structures (e.g. faults causing vertical offsets) within the lateral extent of the reflectors. Furthermore, several reflectors with a opposite dip direction were mapped in the reflection seismic images. In particular, one of these reflections is of greater interest, since it marks the lowermost end of the deposit related reflector. However, in order 
https://doi.org/10.5194/se-2021-101

Preprint. Discussion started: 17 August 2021

(c) Author(s) 2021. CC BY 4.0 License.

(c) (i)

to reveal the true 3D structure and to better evaluate the potential resources of the deposits, a sparse 3D seismic survey was conducted in April/May 2019 (Malehmir et al., 2021). The results of a conventional post-stack time migration workflow were shown in Malehmir et al. (2021). Here, we present the corresponding results of a pre-stack depth imaging workflow applied to the same data set.

70 For the previously acquired 2D seismic data, Bräunig et al. (2019) demonstrated a suitable imaging workflow with pre-stack depth migration as the last step resulting in a final depth image. Furthermore, Bräunig et al. (2019) showed that the application of focusing pre-stack depth migration techniques, such as Fresnel Volume Migration (FVM) (Lüth et al., 2005; Buske et al., 2009), Coherency Migration (Hlousek et al., 2015a) or Coherency based Fresnel Volume Migration (Hlousek et al., 2015b) can improve the resulting image of the mineralization for the $2 \mathrm{D}$ data set and therefore allows for a more detailed interpretation

75 compared to a simple KPSDM approach. Following these promising results, we applied the focusing FVM approach also to the new 3D data set and compare it to the result of a basic KPSDM.

As an input for both migration techniques a good macro velocity model in depth is needed. However, creating such a reliable migration velocity model can be a challenging task for hard rock settings, since clear reflections are often missing which are required for picking velocities within conventional velocity semblance analysis. What is also very special in such hard rock

80 environments is the relatively homogeneous velocity distribution within crystalline formations, combined with relatively small velocity variations between different rock types and typically slightly increasing velocities with depth. However, velocities up to $6000 \mathrm{~m} / \mathrm{s}$ often appear already at shallow depths. In combination with an additional weathering layer in the uppermost part, which is typically characterized by low velocities $(<2000 \mathrm{~m} / \mathrm{s})$ and significant heterogeneity, a strong vertical velocity gradient can often be observed in the shallowest part of the subsurface. A high resolution near-surface velocity model would be required

85 to accurately address this shallow strong velocity gradient (Jones, 2018). This would lead to a densely sampled migration velocity model, and therefore a high computational effort, since the velocities in the hard rock itself varies only very smoothly. Furthermore, the topography plays an important role, as a varying topography may lead to a vertically varying thickness of the low velocity weathering layer. In general, topographical effects can be addressed easily within our pre-stack depth migration implementation since the true elevation for sources and receivers are considered as such.

90 In order to account for these two challenges, i.e. the influence of the near-surface low-velocity weathering layer in combination with a topography, we use 3D refraction static solutions based on a 3D first-arrival travel-time inversion, followed by a shift to the final datum using a constant replacement velocity, which is in the range of the expected near surface bedrock velocity in our investigation area. Static corrections are not as mandatory for pre-stack depth migration when processing land seismic data, including those acquired in hard rock environments, as often argued. They are reasonable in some cases as they basically

95 remove the influence of the complete near surface weathering layer from the data. Since the velocities below the weathering layer are expected to be slowly varying laterally and with depth, a simple macro velocity model can then be used for migration. The static corrections are combined with a constant or a 1D gradient migration velocity model. In our case, this gradient was derived from the previously acquired 2D data set using a migration velocity analysis approach (Bräunig et al., 2019). 
https://doi.org/10.5194/se-2021-101

Preprint. Discussion started: 17 August 2021

(c) Author(s) 2021. CC BY 4.0 License.

(c) (i)

The application of the pre-stack depth migration approach plays a major role as the final step in our workflow. As for the 2D data, we initially applied KPSDM (Schneider, 1978; Buske et al., 1999), resulting in a first 3D seismic depth image of the investigation area. Subsequently, we applied FVM as an extension of KPSDM that limits the migration operator to the Fresnel Volume around back-propagated rays and focuses the image to the physically contributing part of the two-way travel-time isochrone (Lüth et al., 2005; Buske et al., 2009). FVM was applied already successfully to hard rock reflection seismic data in 2D and 3D several times (e.g. Hlousek et al., 2015; Hlousek and Buske, 2016; Riedel et al., 2015; Bräunig et al., 2019), 105 including mineral exploration (Heinonen et al., 2019; Singh et al., 2019). A key point in 3D FVM is the 3D slowness estimation from the recorded data. The slowness is estimated directly from the recorded wavefield using a local slant stack method with the semblance (Neidell and Taner, 1971) for arbitrarily distributed receivers to estimate the most probable direction for the emergent wavefield (Hlousek and Buske, 2016). Hence, the slowness estimation and therefore FVM is completely data driven and needs no a-priori information on strike and dip directions of the expected structures. This ability to image arbitrary dips

110 and strikes without a priory information makes FVM extremely robust for imaging in hard rock environments, especially when the signal to noise ratio is low, the coverage of the data is sparse and the impedance contrasts of the expected structures are small as shown in Heinonen et al. (2019). Therefore, we used FVM as the preferred imaging technique for the 3D data set here in this study. 
https://doi.org/10.5194/se-2021-101

Preprint. Discussion started: 17 August 2021

(c) Author(s) 2021. CC BY 4.0 License.

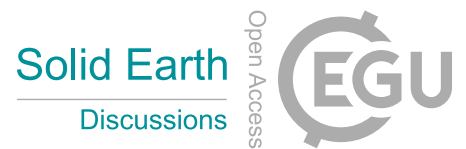

(c) (i)
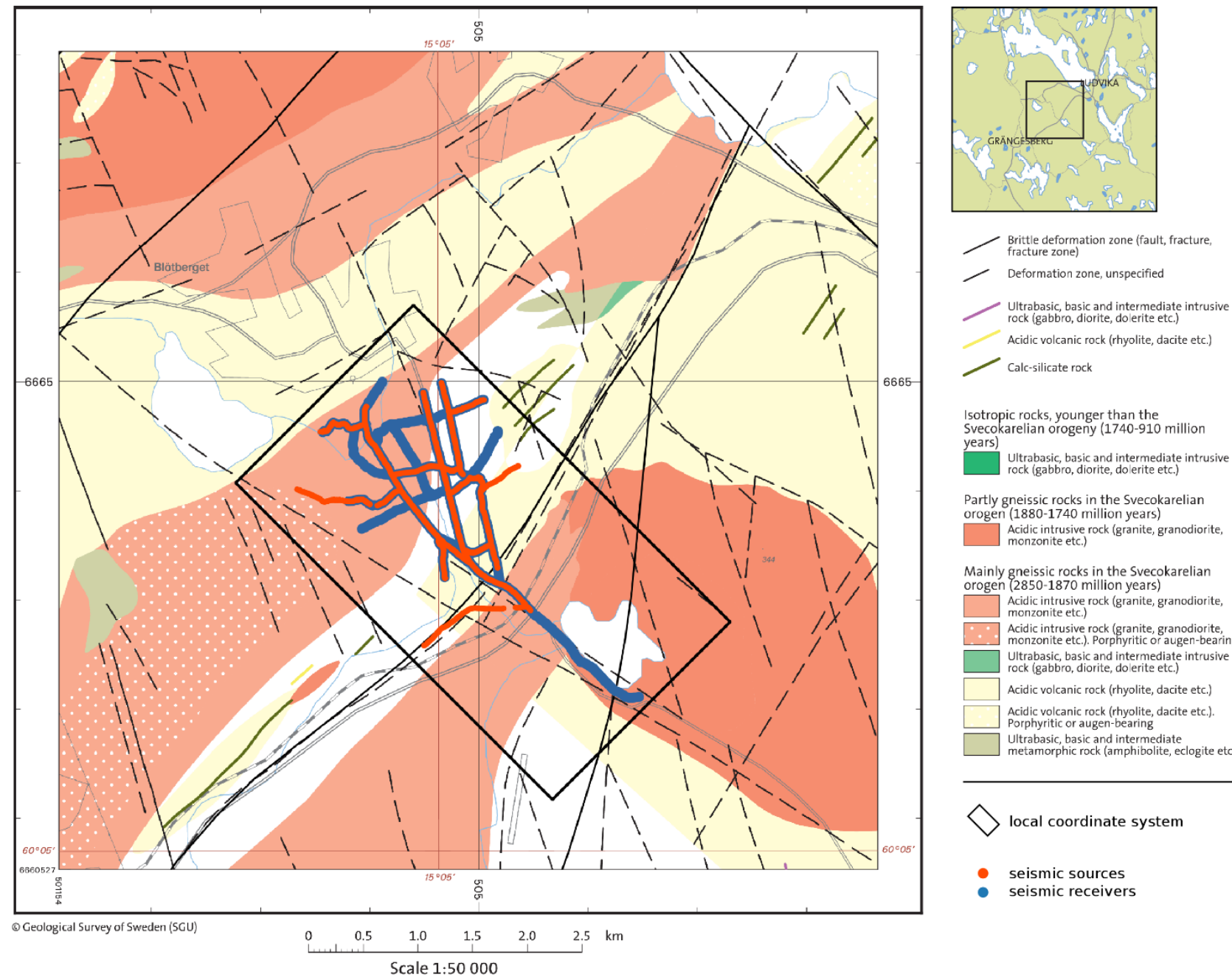

Isotropic rocks, younger than the Svecokarelian orogeny (1740-910 million years) Ultrabasic, basic and intermediate intrusive
rock (gabbro, diorite, dolerite etc)

Partly gneissic rocks in the Svecokarelian arogen (1880-1740 million years)

Acidic intrusive rock (granite, granodiorite,
monzonite etc.)

Mainly gneissic rocks in the Svecokarelian orogen (2850-1870 million years) Acidic intrusive rock (granite, granodiorite, Acidic intrusive rock (granite, granodiorite, Ultrabasic basic and intermediate intrusive rock (gabbro, diorite, dolerite etc.) Acidic volcanic rock (rhyolite, dacite etc.) Acidic volcanic rock (rhyolite, dacite etc.) Porphyritic or augen-bearing Ultrabasic, basic and intermediate
metamorphic rock (amphibolite, eclogite etc.)

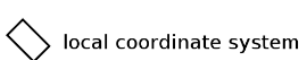

- seismic sources

- seismic receivers

115 Figure 1: Survey layout with source (red) and receiver (blue) positions of the 3D survey and the local coordinate system used for first arrival traveltime tomography and imaging (black box) on top of the bedrock map. Courtesy of the Geological Survey of Sweden. 


\section{Seismic data acquisition}

The seismic data set for our study was acquired in Spring 2019 in the Bergslagen mining district in central Sweden. Bergslagen is historically the most diverse mineral endowment in Sweden and contributed to the industrial development and wealth of the Swedish society. Apart from iron ores, massive sulphide mineralization ( $\mathrm{Zn}$ and $\mathrm{Pb}$ ) is also significant in the district. Figure 1 shows a geological map together with the geometry of the seismic survey, including all source and receiver locations in red and blue, respectively. The black rectangle indicates the lateral extension and location of the resulting 3D seismic cube described in detail in the following chapter. Figure 2 shows a 3D perspective view onto the known mineralization (e.g. red and

130 blue surfaces), the surface topography and the source and receiver locations of the 3D survey.

The image cube (black rectangle in Figure 1, white box in Figure 2) has a horizontal extension of $2.3 \mathrm{~km} \mathrm{x} 4.1 \mathrm{~km}$. Its longer axis is oriented in NW-SE direction and follows the central line of the 3D survey, which is identical to the previous 2D seismic survey acquired in 2015 and 2016. Its shorter axis is perpendicular to it and runs almost parallel to the strike direction of the main geological units of interest. The vertical (depth) extension of the cube in Figure 2 is $2.25 \mathrm{~km}$.

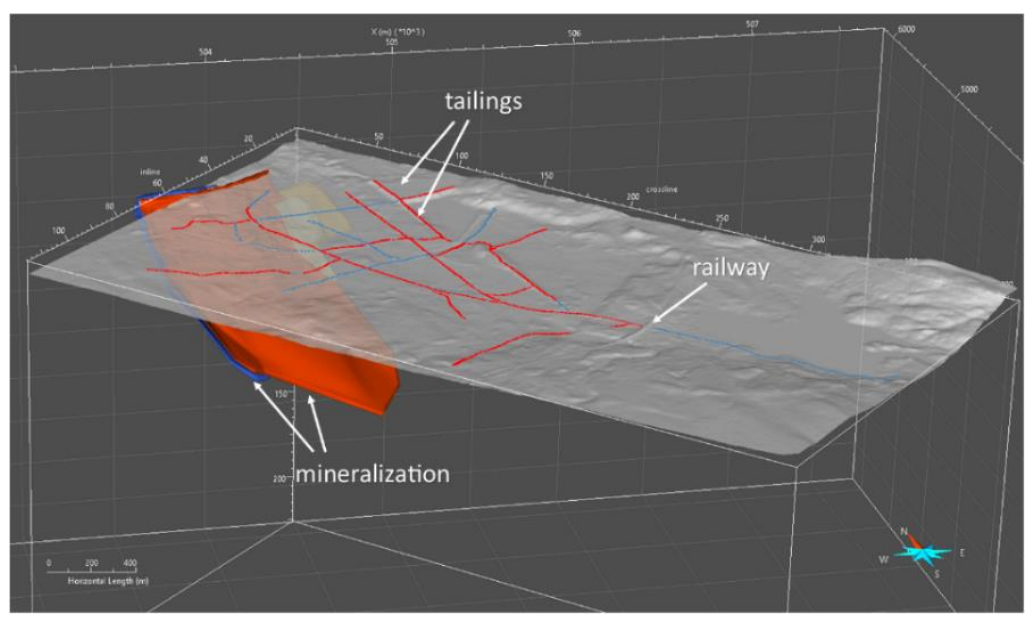

Figure 2: Perspective view onto the known mineralization bodies (red and blue layers/bodies) in the Blötberget area, together with the source and receiver positions (red and blue dots, respectively) of the 3D survey and a digital elevation model showing the topography within the survey area.

140 For the 3D survey a combination of cabled and wireless receivers was deployed with 1266 receiver points in total. The 32t Vibroseis source of TU Bergakademie Freiberg was used as seismic source with a linear up-sweep of $20 \mathrm{~s}$ length, a frequency bandwidth of 10-160 Hz and vertical stacking of three sweeps per source point. Overall 1056 source points were acquired, distributed mainly along existing forest roads in the area and resulting in a rather irregular and sparse 3D geometry. The internal receiver spacing along the lines was $10 \mathrm{~m}$ or $20 \mathrm{~m}$, respectively. The north-western part of the investigation area is covered relatively well with source-receiver azimuths in all directions, while the south-eastern part contains only receiver points but 
https://doi.org/10.5194/se-2021-101

Preprint. Discussion started: 17 August 2021

(c) Author(s) 2021. CC BY 4.0 License.

(c) (i)

no shot points along the central line. The layout was chosen like that since the mineral deposit related structures of interest are striking from southwest to northeast and are dipping to the southeast. As a consequence of this survey layout, the near-surface part is covered and illuminated well in 3D, while the deeper central parts are less well covered and illuminated. The layout of the survey was caused by two restrictions related to environmental and logistical issues: the first was the restriction for the used Vibroseis truck to the available roads, which was a problem for the south-eastern part of the central line which the truck could not enter due to weight limits on the access roads. The second limitation was related to the usage of cabled receivers and limited wireless recorders available for the survey. Moreover, the majority of the used wireless receiver system required a communication between single receivers in the field so that a quasi-line-wise setup was necessary. A minor number of receivers were fully autonomous recording wireless stations, and these receivers were used to cross the main road in the southwestern part of the layout as well as distributed along the existing road. All acquisition parameters are summarized in Table 1.

Table 1: Acquisition parameters of the 3D reflection seismic survey.

\begin{tabular}{ll}
\hline Acquisition parameters & \\
\hline Number of live channels & 1266 (fixed spread) \\
Acquisition system & Sercel 408 (cabled and wireless), Wireless Seismic \\
& RT2 (wireless) \\
Sampling interval & $1 \mathrm{~ms} / 2 \mathrm{~ms}$ \\
Receiver spacing & $10 \mathrm{~m} / 20 \mathrm{~m}$ along lines \\
Receiver type & Vertical component geophones (4.5 Hz, 10 Hz and 28 \\
& Hz) \\
Number of source points & 1056 (along receiver lines) \\
Source spacing & $10 \mathrm{~m}$ along lines \\
Source type & $32 \mathrm{t}$ Vibroseis truck \\
Sweep parameters & $10-160$ Hz linear upsweep, 20 s sweep length, $60 \%$ \\
& peak force \\
Number of sweeps per source point & 3 \\
\hline
\end{tabular}


https://doi.org/10.5194/se-2021-101

Preprint. Discussion started: 17 August 2021

(c) Author(s) 2021. CC BY 4.0 License.

(c) (i)

\section{Depth imaging}

\subsection{Data pre-processing}

In general, the data set exhibits an excellent data quality for a hard rock setting with good signal-to-noise ratio, sharp first arrivals and several clear reflections visible already in the raw shot gathers (Figure 3a). The data set has been pre-processed following the processing flow listed in Table 2 . The focus in the signal processing sequence was on a consequent suppression of surface waves and boosting the coherency of the reflected signals from the ore bodies and their surrounding structures. Figure 3 shows an exemplary single shot gather before and after pre-processing. It is clearly visible that the low frequency surface waves were successfully suppressed and that the visible reflection signals are enhanced. The latter appear clearer and more continuous along the single receiver lines and are traceable throughout the whole shot gathers (see yellow arrows in

170 Figure 3b).

Table 2: Pre-processing flow applied to the data set. All steps up to Amplitude scaling are identical up to step 5 in Table 2 of the processing in Malehmir et al. (2021).

\begin{tabular}{ll}
\hline Processing parameters & \\
\hline Sweep correlation & Yes \\
Vertical stacking & 3 sweeps per source location \\
Geometry setup & 3D, sparse \\
Amplitude normalisation & Surface-consistent for shots and receivers \\
Minimum-phase conversion & Based on matching filter using theoretical sweep \\
Refraction statics & Apply static correction based on refraction traveltimes, \\
& shift to final datum of $250 \mathrm{~m}$ using $5000 \mathrm{~m} / \mathrm{s}$ \\
AGC & replacement velocity \\
Spiking deconvolution & $200 \mathrm{~ms}$ window length \\
Bandpass filter & $80 \mathrm{~ms}$ operator length, single trace \\
Surface wave attenuation & $15-35-145-165 \mathrm{~Hz}$ \\
FX deconvolution & Wavelet-transform based (v $\leq 2700 \mathrm{~m} / \mathrm{s})$ \\
Amplitude scaling & Yes \\
Top mute & Whole-trace RMS amplitude balancing \\
\hline
\end{tabular}


https://doi.org/10.5194/se-2021-101

Preprint. Discussion started: 17 August 2021

(C) Author(s) 2021. CC BY 4.0 License.

(a)

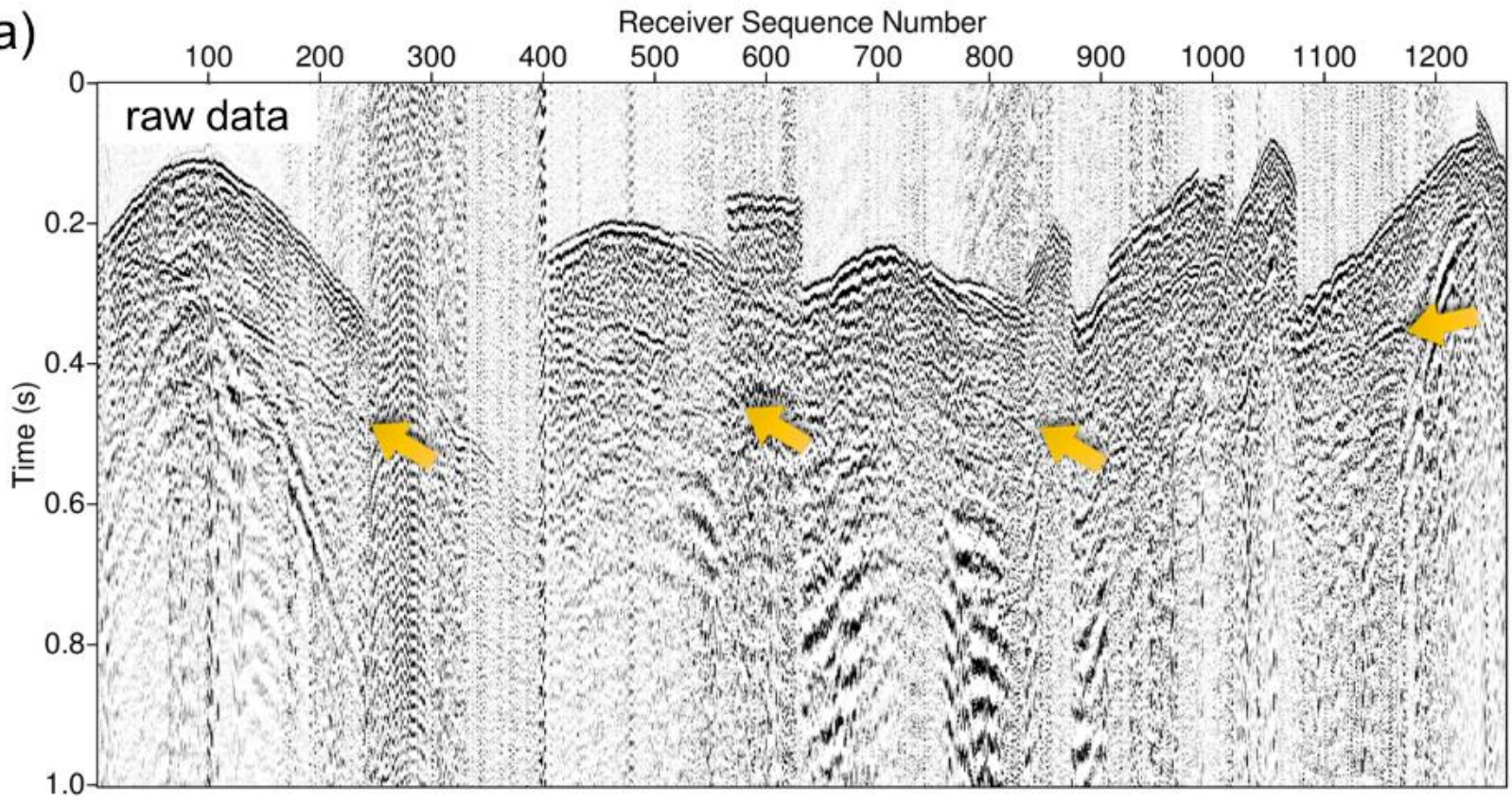

(b)

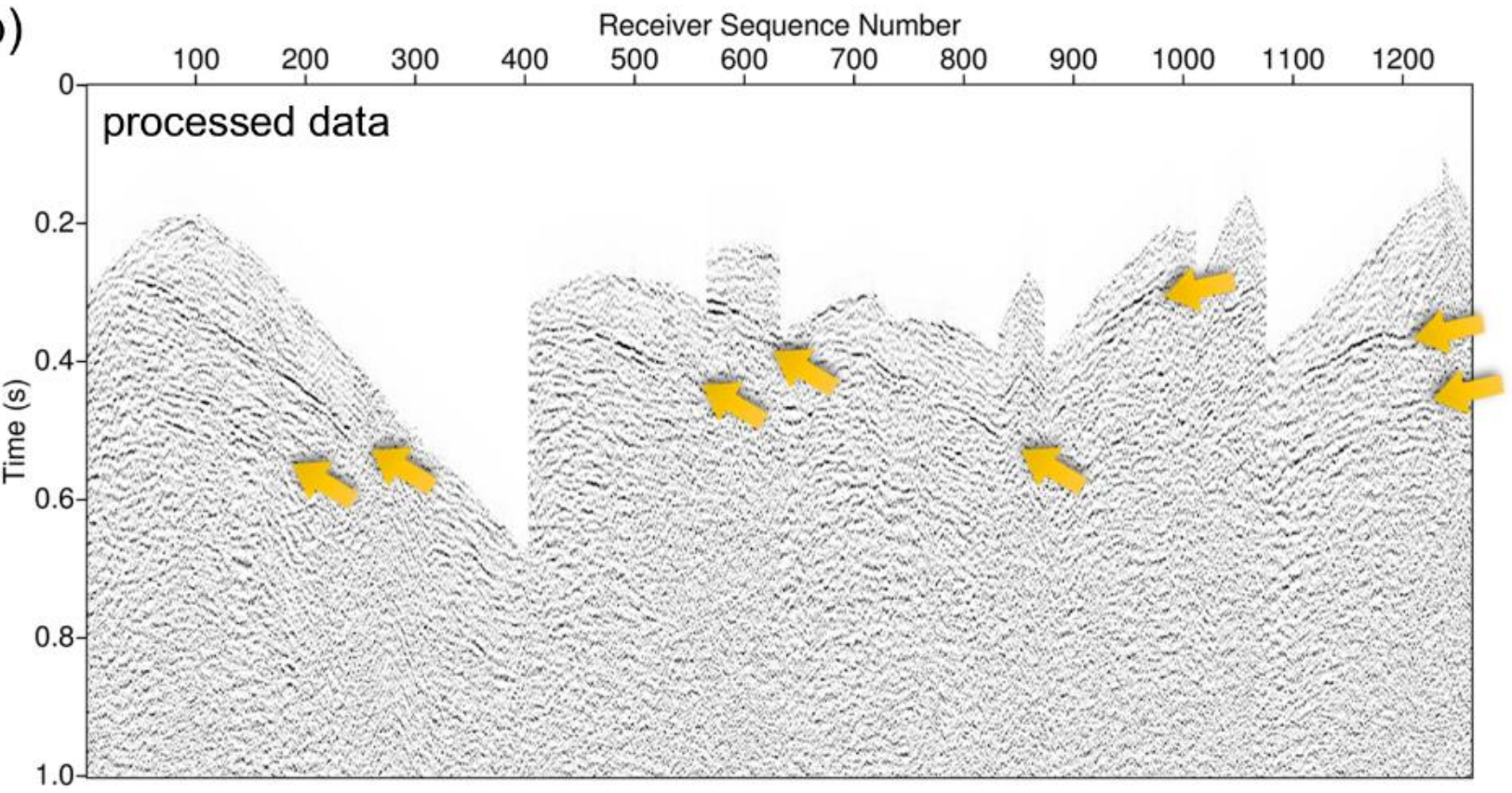

Figure 3: Exemplary shot gather of the raw data (a) and after pre-processing (b) as described in Table 2. The source position of the shown shot gather is located close to receiver number 1250. The yellow arrows mark some visible reflections caused by the mineralization in the data. 
https://doi.org/10.5194/se-2021-101

Preprint. Discussion started: 17 August 2021

(c) Author(s) 2021. CC BY 4.0 License.

(c) (i)

\subsection{Refraction statics}

The first arrivals were manually picked for the whole data set and used to calculate refraction statics using two methods: (1) generalized refraction traveltime inversion (GLI3D, Hampson and Russell, 1984) and (2) first-arrival traveltime tomography (FATT) (Zhang and Toksöz, 1998). Both methods were implemented in Geotomo Inc. TomoPlus software. GLI3D is a very

185 robust and industry-proven technique to invert refraction traveltimes using layer-based model. Velocities in layers can vary laterally, except the shallowest one. FATT can be used to derive static solution in form of so-called tomostatics (e.g., Bräunig et al., 2019). This method can be advantageous over layer-based inversion in case of strong topography or lack of clearly defined refraction interfaces, e.g., in mountainous areas (Cyz and Malinowski, 2013). On the other hand, there is an ambiguity in determination of the intermediate datum in tomostatics, which can affect final statics values. In case of the hard rock seismic,

190 usually a simple two-layer refraction solution is used to represent glacial sediments and the bedrock.

For Ludvika data we tested both methods, using all the available picks in the inversion. GLI3D solution was based on a twolayer model. For the residual statics calculation only offsets between $200 \mathrm{~m}$ and $2000 \mathrm{~m}$ were used. Looking at the commonreceiver and common-shot stacks without statics application (Figure 4a and 4d), it is clear that the statics is a significant issue in our data. Although the receiver and shot static values obtained using both methods do not differ significantly, one can clearly

195 see that there is a better alignment of the energy visible in the stacks produced with the application of the GLI3D statics (Figure $4 \mathrm{c}$ and $4 \mathrm{f}$ ), especially for the shot stack. Therefore, our final choice was to apply the GLI3D-derived statics to the data. Such a choice allowed us to avoid a potential problem related to the fact, that in order to properly use tomostatics in the depthimaging workflow, we should have applied only the residual part of the statics to the data and set the migration traveltime calculation grid fine-enough to be able to reproduce the long-wavelength part of the tomostatics. It could have been computationally too expensive in 3D (Jones, 2018). 

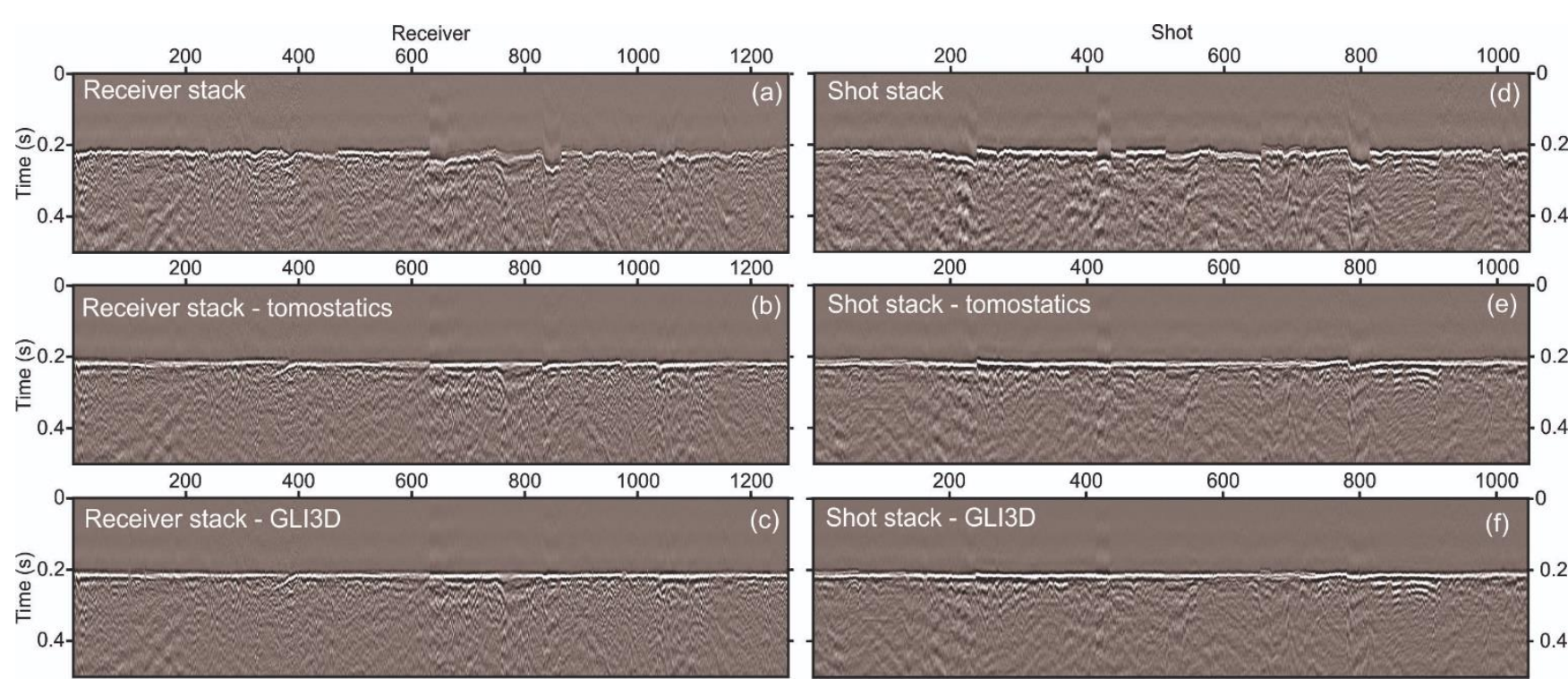

Figure 4: Common-receiver (panels a-c) and common-shot stacks (panels d-f) calculated for the data after simple linear-moveout (LMO) correction and with the application of the tomostatics (b-e) and GLI3D statics (c-f).

\subsection{Migration Velocity Model Building}

Here, the inverted near surface velocity model was only used to calculate static corrections, in contrast to the imaging workflow described in Bräunig et al. (2019) where the near surface velocity model was also used directly as part of the migration velocity model. For migration a reasonable macro velocity model for the bedrock and deeper units is needed. Borehole investigations (Maries et al., 2011) have shown that the bedrock velocities are varying mainly around $5600 \mathrm{~m} / \mathrm{s}$ down to the target depth. Bräunig et al. (2019) used a Migration Velocity Analysis (MVA) approach to extend the migration velocity model below the shallow tomographic model down to the target depth. As a constraint, Common Image Gathers with the mineralization related reflector as a key horizon were used to iteratively update and improve the velocity model. Therefore, the derived velocity model can be considered to be reliable down to the expected mineralization. Here, we use the MVA part of the derived migration velocity model, which is basically a 1D gradient velocity model with slightly increasing velocities with depth. At the top of the velocity model we use the replacement velocity, which was also used during static corrections, as a starting value for the $1 \mathrm{D}$ gradient model. The velocity values and the corresponding depths are summarized in Table 3 . The values are linearly interpolated between the depth intervals and are kept constant within the depth intervals. 
https://doi.org/10.5194/se-2021-101

Preprint. Discussion started: 17 August 2021

(c) Author(s) 2021. CC BY 4.0 License.

(c) (i)

Table 3: 1D migration velocity model.

\begin{tabular}{ll}
\hline Depth $(\mathbf{m})$ & Velocity $(\mathbf{m} / \mathbf{s})$ \\
\hline-250 to -210 & 5000 \\
500 to 1250 & 5600 \\
1500 & 6000 \\
2000 & 6500 \\
\hline
\end{tabular}

\subsection{Pre-stack Depth Migration}

All pre-stack depth migrations were applied to each shot separately on a uniform grid with a grid-spacing of $10 \mathrm{~m}$ in each direction. The result is a 3D image for each shot-gather which are finally stacked to the complete image (Buske, 1999). As a first step, a constant migration velocity of $5600 \mathrm{~m} / \mathrm{s}$ as a representative value for the bedrock in the investigation area was chosen for KPSDM in order to get an overview about the main structures and an impression of the reliability and robustness of the applied pre-stack depth migrated approach. Figure 5 shows a vertical depth slice of the resulting image cube along the Northeast-Southwest direction through the central part of the investigation area. Figure 5a shows the plain image with two marked reflectors. The yellow arrows mark the expected main mineralization reflector, which is dipping to the southeast. At its lower end, this reflector is bounded by a crosscutting reflector (blue arrows) which is dipping into the opposite direction. This crosscutting reflector was also present in the result of the earlier 2D survey, but here this reflector appears much clearer and sharper. Even more reflections can be found already in this 3D KPSDM image, which will be described in detail using the FVM image below. Here we concentrate on the two mentioned reflectors for the evaluation of the imaging techniques and the used velocity model. Figure 5b shows the KPSDM image together with the model layers of the known mineralization. The dip direction and dip angle are well visible in the seismic image. However, a detailed comparison of the image and the modelled mineralization shows that the reflector is imaged around $50 \mathrm{~m}$ below the known model layers. The reason for this mismatch is the too simple constant velocity of $5600 \mathrm{~m} / \mathrm{s}$ used for the migration, which appears to be too high. Choosing iteratively different constant velocities for migration to find a representative effective medium velocity could improve the tie between the depths of the imaged reflector and the corresponding mineralization. However, such a calculation of an average medium velocity will not consequently result in a robust migration velocity model in order to improve depth positioning as well as the image quality along the reflectors throughout the 3D model. Therefore, we omit this iterative improvement but rather concentrate on a more reliable 3D migration velocity model in the next step. 
https://doi.org/10.5194/se-2021-101

Preprint. Discussion started: 17 August 2021

(c) Author(s) 2021. CC BY 4.0 License.
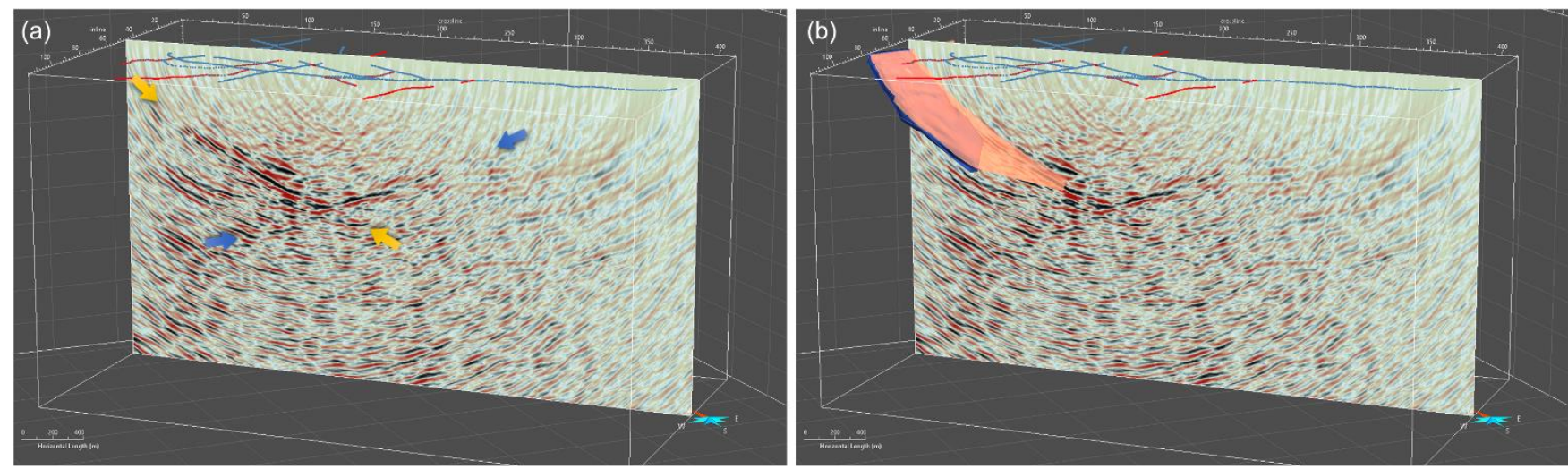

245 Figure 5: Depth slice through the KPSDM result using a constant velocity of $5600 \mathrm{~m} / \mathrm{s}$ for migration. (a) without and (b) with the known mineralization layers in red and blue. The yellow and blue arrows in (a) mark the image of the main mineralization reflector and a crosscutting reflector dipping in the opposite direction, respectively.
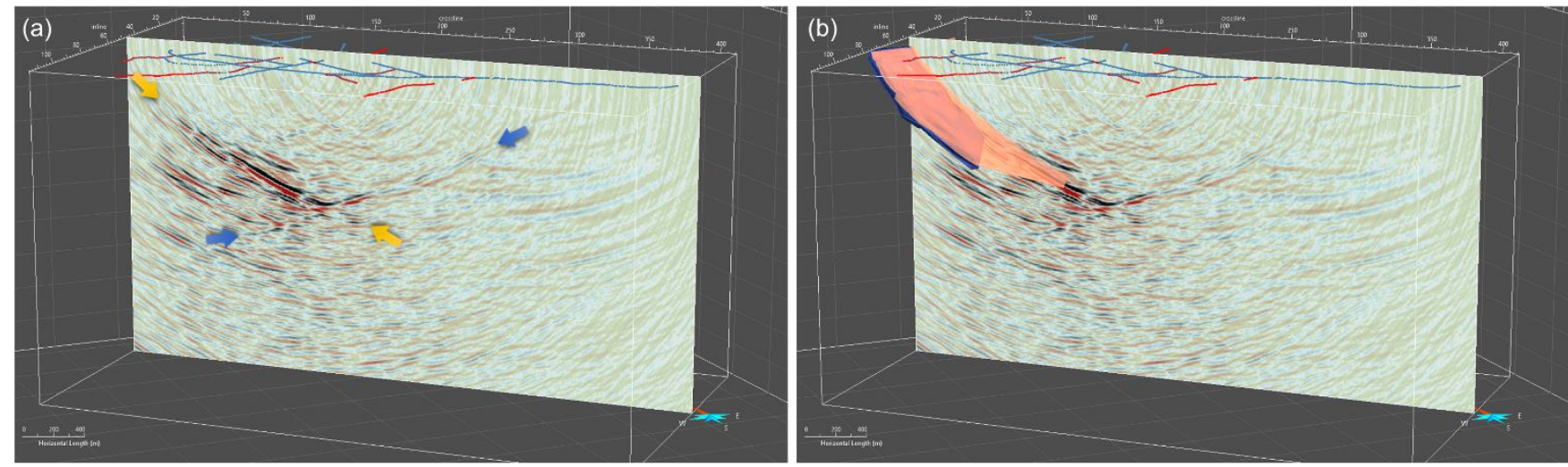

Figure 6: Depth slice through the FVM result using a constant velocity of $5600 \mathrm{~m} / \mathrm{s}$ for migration. (a) without and (b) with the known mineralization in red and blue. The arrows in (a) mark the image of the main mineralization reflector and a crosscutting reflector dipping in the opposite direction. The shown vertical depth slice is at the same location as the slice shown in Figure 5.

Before using this 3D migration velocity model, we wanted to improve the reflection seismic image and therefore applied the focusing 3D FVM approach. Figure 6 shows the same vertical depth slice as in Figure 5 but here for the FVM image cube. The arrows mark the same reflectors as in the KPSDM image: yellow arrows for the main mineralization and blue arrows for the crosscutting reflector. When comparing the KPSDM and FVM images (Figure 5 and 6, respectively) a lot of similarities but also several significant differences can be observed. Since the used migration velocity model and the basic imaging technique are identical, the imaged structures appear at the same position and depth. Furthermore, all observable structures in the FVM image are already part of the KPSDM image, but they are partly covered by incoherent noise and migration artefacts in the KPSDM image. In general, the FVM image appears much cleaner and clearer as the KPSDM image. This is caused by

260 the restriction to the Fresnel zone along the corresponding travel-time-isochrones during FVM. Additionally, incoherent noise is reduced in the whole image and the coherent reflections are more outstanding. Due to the improved signal to noise ratio, the 
https://doi.org/10.5194/se-2021-101

Preprint. Discussion started: 17 August 2021

(C) Author(s) 2021. CC BY 4.0 License.

crosscutting reflector appears more continuous. Especially, its shallow part in the south-east is well visible in the FVM image (upper blue arrow in Figure 6a), while it is covered by incoherent noise in the KPSDM image (Figure 5a). Overall, the imaged reflectors are more continuous and easier to identify in the FVM result.

265 As the next step, the constant migration velocity model was replaced by the 1D gradient model described above. Figure 7 shows the FVM result using this 1D gradient model for slowness calculation, raytracing within FVM and travel-time calculation. The shown slice is located at the same position as the slices for the KPSDM image and the FVM image using a constant migration velocity (see Figure 5 and Figure 6, respectively). Here, the same main structures can be identified. The reflector related to the main mineralization is marked again with yellow arrows. Compared to the previous results it is imaged slightly shallower but with approximately the same dip angle. The reflector itself is more coherent than in the case of a constant migration velocity (Figure 6) and the image of the reflector appears straighter in its shape. The crosscutting reflector, marked with blue arrows in Figure 7a, is also imaged at shallower depths. In contrast to the main mineralization, the dip of the crosscutting reflector is changing. When using the $1 \mathrm{D}$ gradient velocity model for migration, the reflector appears steeper than in the constant velocity migration result. Furthermore, the image of the reflector is more coherent and exhibits a higher amplitude. Figure 7b shows the FVM image based on the 1D gradient together with the known mineralization (blue and red bodies). The image of the reflector coincides precisely with the depth position and dip of the known mineralization. At the lower end of the model, the imaged reflector continues down to greater depth and further to the southeast, where it ends at the crosscutting reflector.
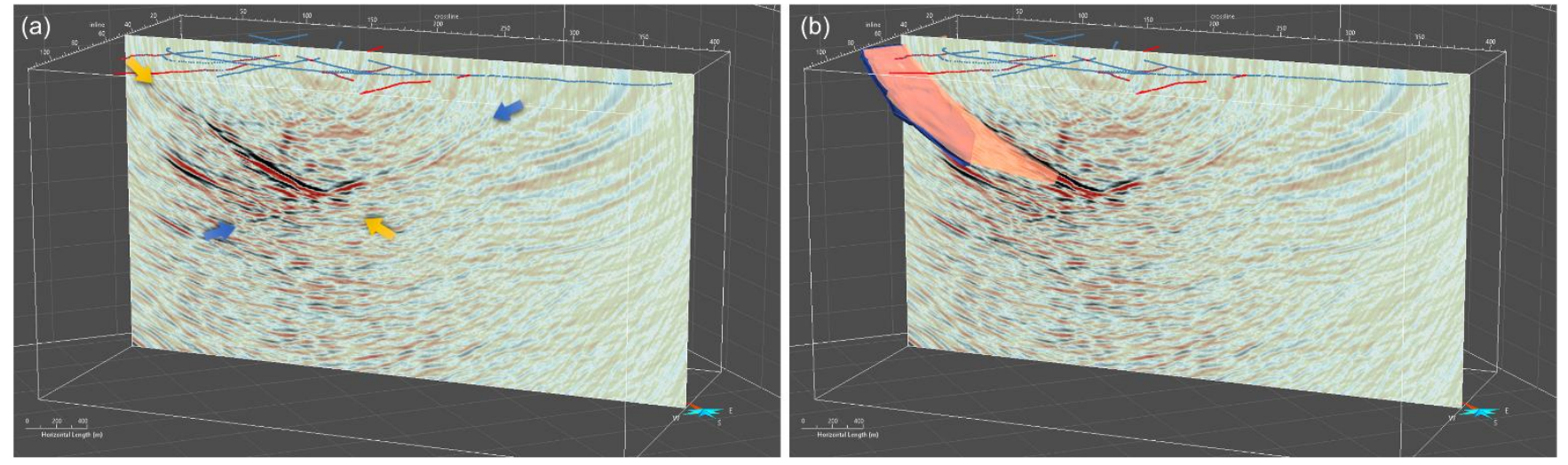

280 Figure 7: Depth slice through the FVM result using the 1D migration velocity model including information from MVA (Table 1): (a) without and (b) with the known mineralization in red and blue. The arrows in (a) mark the image of the main mineralization reflector and a crosscutting reflector dipping in the opposite direction (compare Figure 5 and 6 ). The shown slice is at the same location as the slice shown in Figure 5 and 6.

285 Figure 8 shows a selection of more vertical depth slices through the FVM image cube based on the result using the 1D gradient velocity model. The slices are all oriented from northwest to southeast and have a spacing of 100-200 m. The location of each slice in the local coordinate system is indicated in the upper right corner of each subfigure. The slice in Figure 8a is located in 
https://doi.org/10.5194/se-2021-101

Preprint. Discussion started: 17 August 2021

(c) Author(s) 2021. CC BY 4.0 License.

\section{(c) $\underset{\mathrm{BY}}{\mathrm{BV}}$}

the northeast of the investigation area at $\mathrm{y}=500 \mathrm{~m}$. It shows a prominent reflector marked with $\mathrm{M} 1$ and this reflector can directly be correlated to the upper main mineralization (red layer in Figure 2). In this slice, the image of the reflector appears relatively curved and interrupted in the middle part. The curvature can be explained by the fact that the slice is located at the boundary of the investigation area and is therefore insufficiently illuminated. This could also be the reason for the interruption in the middle part of the reflector. Below the main reflector M1, several other weaker reflectors can be identified. In the second slice at $y=700 \mathrm{~m}$ (Figure $8 \mathrm{~b}$ ) the reflectors are better illuminated. Now, the reflector M1 appears as a strong coherent reflector with only a slight curvature at the upper north-western end. It dips with about $30^{\circ}$ to the southeast and is imaged between $240 \mathrm{~m}$ and $840 \mathrm{~m}$ depth. The dip angle and dip direction are in good agreement with the dip of $25^{\circ}$ to $30^{\circ}$ in the time migrated and depth converted image of Malehmir et al. (2021). The reflectivity below the M1 reflector in Figure $8 \mathrm{~b}$ appears more coherent than in Figure 8 and distinct reflections can be identified which are marked by a green arrow. Furthermore, the previously described crosscutting reflector (compare Figure 7) is well visible (C1, blue arrow in Figure 8b). It dips with an angle of approximately $25^{\circ}$ to the northwest and is imaged between $400 \mathrm{~m}$ and $740 \mathrm{~m}$ depth. The reflectors $\mathrm{M} 1$ and $\mathrm{C} 1$ are intersecting at $725 \mathrm{~m}$ depth, where the $\mathrm{C} 1$ reflector marks the lower end of the coherent and straight image of the $\mathrm{M} 1$ reflector.

Beside the $\mathrm{C} 1$ reflector, a second weaker reflector is visible at shallower depth (blue arrow). It dips with around $20^{\circ}$ to the southeast and is imaged between $160 \mathrm{~m}$ and $360 \mathrm{~m}$ depth. This reflector is traceable only over some slices. At $\mathrm{y}=900 \mathrm{~m}$ (Figure $8 \mathrm{c}$ ) it is almost not visible anymore. The M1 reflector appears again as a sharp and strong reflector. The dip is still around $30^{\circ}$, but the reflection can be traced between $35 \mathrm{~m}$ and $830 \mathrm{~m}$ depth with a spatial extent of approximately $1700 \mathrm{~m}$ in this slice. Again, it is crossed at its lower end at $780 \mathrm{~m}$ depth by the $\mathrm{C} 1$ reflector. The $\mathrm{C} 1$ reflector is imaged slightly deeper than in the previous slice and shows approximately the same dip angle of about $25^{\circ}$. This changing depth suggests a $3 \mathrm{D}$ orientation of this reflector, which is not perpendicular to the slices selected here. Since the imaged depth is increasing, the strike direction is more north-south than northeast-southwest. However, it is imaged clearly between $250 \mathrm{~m}$ and $990 \mathrm{~m}$ depth. Above the intersection with M1 it is imaged as one continuous reflector, while it appears more disrupted below the intersection. There, it also intersects other coherent reflectors which are oriented subparallel to the M1 reflector (green arrow). This reflector is imaged between $500 \mathrm{~m}$ and $1000 \mathrm{~m}$ depth and is dipping with almost the same angle as reflector M1 to the southeast. The lower end of this reflector is also marked by the crosscutting $\mathrm{C} 1$ reflector. Besides these main reflections, also some deeper less strong and coherent reflectors can be observed. They are all dipping into the same direction and with an angle comparable to the M1 reflector.

315 In the following slice at $\mathrm{y}=1000 \mathrm{~m}$ (Figure $8 \mathrm{~d}$ ) the overall structures are imaged in a similar pattern. The depth of the $\mathrm{C} 1$ reflector is slightly increasing, the reflector appears less continuous as before and shows a small offset at $480 \mathrm{~m}$ depth. The M1 reflector also appears less continuous, especially in the upper part it is less sharp and coherent. The whole reflectivity is more complex along the reflector itself. The deeper subparallel reflector also appears less coherent and continuous together with a broadened signal, which also accounts for a more complex 3D structure for the M1 reflector and the underlying reflectivity. This impression is confirmed by the image in the next slice at $\mathrm{y}=1100 \mathrm{~m}$ (Figure 8e). There, the reflector M1 can still be identified, but is also intersected by a second, slightly deeper reflector with the same dip direction (M2). Also, the 
https://doi.org/10.5194/se-2021-101

Preprint. Discussion started: 17 August 2021

(c) Author(s) 2021. CC BY 4.0 License.

(c) (i)

underlying subparallel reflectivity appears even more complex and less distinct than before. All reflectors dipping to the southeast have in common that they are confined by the crosscutting $\mathrm{C} 1$ reflector at their lower end. The image becomes again a little bit clearer in the slice at $\mathrm{y}=1200 \mathrm{~m}$ (Figure 8f). There the M2 reflector becomes the most prominent and coherent reflector. It is imaged between $190 \mathrm{~m}$ and $770 \mathrm{~m}$ depth and dips with an angle of about $30^{\circ}$ (the same dip as M1 reflector) to the southeast. The M1 reflector can be identified only in deeper parts between $550 \mathrm{~m}$ and $780 \mathrm{~m}$ depth with a slightly steeper angle than the M2 reflector. Below these two reflectors, again some parallel reflectors are visible with approximately the same dip direction (marked with two green arrows). The $\mathrm{C} 1$ reflector is still visible, although the signal is weaker compared to the previous slices. Here, several other reflectors with a comparable dip direction are present and marked with C0, C2 and C3.

330 These reflectors exhibit a shorter spatial extent compared to the others and are traceable only over some adjacent slices. Reflectors C2 and C3 can be found also in the next slice at $\mathrm{y}=1300 \mathrm{~m}$ (Figure 8g). They appear approximately at the same location, while the $\mathrm{C} 1$ reflector is not visible anymore. The same applies for the $\mathrm{M} 1$ reflector which is no longer distinguishable from the reflector M2. The reflector M2 is imaged between $180 \mathrm{~m}$ and $880 \mathrm{~m}$ depth, the underlying parallel reflectors (green arrows) are still visible but less distinct than before. The reflectivity in this area is more diffuse here. Although reflector $\mathrm{C} 1$ is not directly visible, the reflectivity of the M2 reflector and the underlying reflectors end along a line which has the same dip as the $\mathrm{C} 1$ reflector before. The reflectivity in the last slice at $\mathrm{y}=1500 \mathrm{~m}$ (Figure $8 \mathrm{~h}$ ) is again less diffuse. The M2 reflector is imaged again sharper but also steeper $\left(35^{\circ}\right)$ as before. The lower end is confined by an almost horizontal reflector (H1). The reflector C3 is still visible and shows a slightly listric shape. The underlying reflectivity (green arrows) is still present in this image.

340 The visibility of the important structures in the seismic volume can be summarized as follows: the reflectors M1 and M2 can be traced over all shown slices. Since they are crossing each other and intersecting in some slices it is not always possible to distinguish between both reflectors. In all shown slices an underlying reflectivity can be observed. It consists of partly distinct reflectors which are dipping in the same direction and with a comparable dip angle as the M1 and M2 reflectors. The lower end of this reflectivity and the M1 and M2 reflectors is confined by the crossing C1 reflector which has an apparent dip in the opposite direction. Since the imaged depth is increasing for slices to the southwest, the strike direction of this reflector appears more towards the north-south than the northeast-southwest direction. This orientation also explains why this reflector vanishes in the slices in the southwest, because it is not illuminated anymore by the combination of sources and receivers. However, the reflectivity of the M1 and M2 reflectors as well as the reflectivity of the underlying reflectors still ends at a line which could be an indirect hint for the lateral continuation of the $\mathrm{C} 1$ structure. A more detailed geological interpretation in relation to the known structures is given in the following section. 

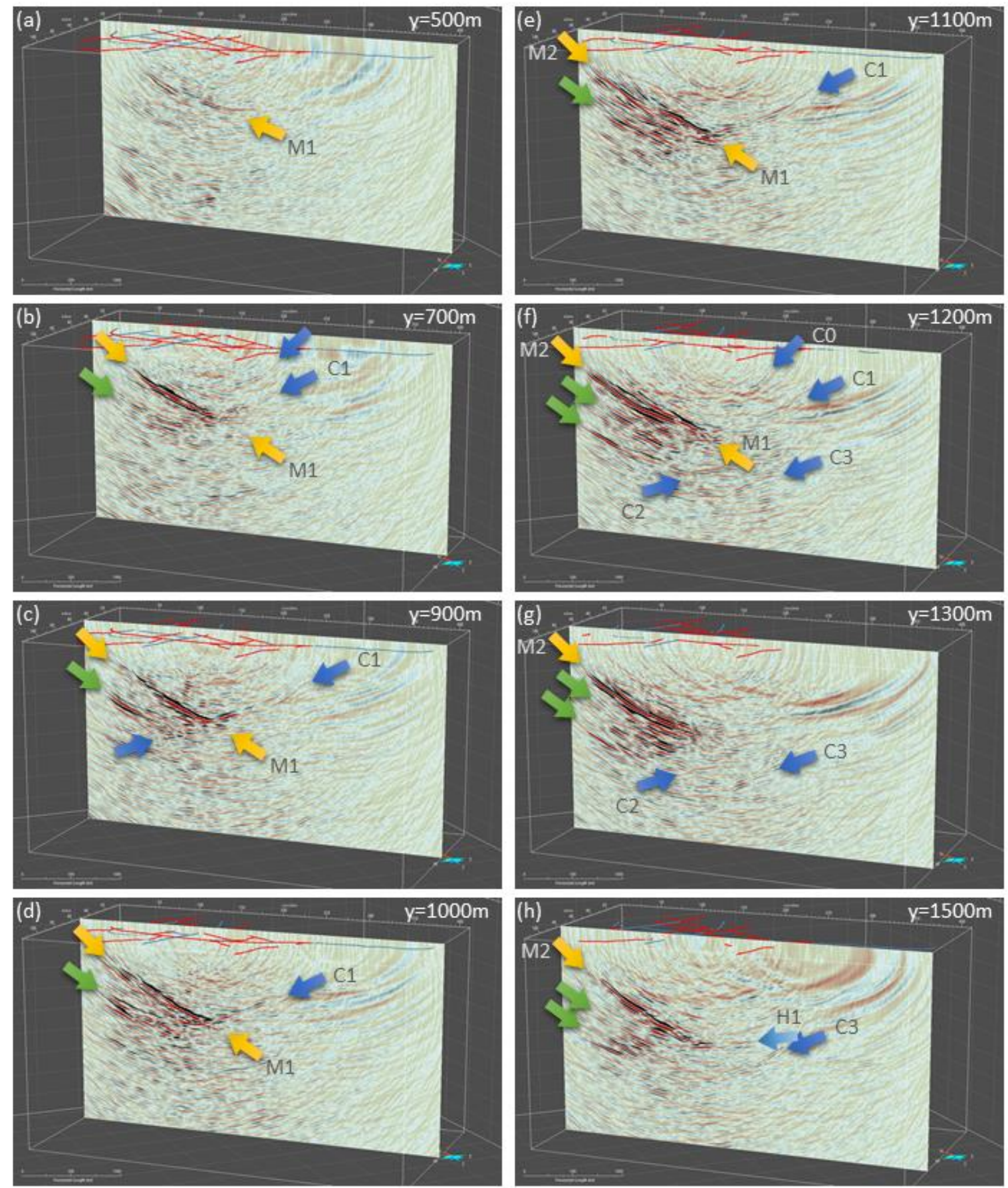

Figure 8: Depth slices through the final FVM result based on the 1D migration velocity model. The slices in (a) to (h) are spaced by 100-200 $\mathrm{m}$ in y-direction. Several reflectors are named and marked with arrows: Yellow marked reflectors correspond to the known mineralization, reflections marked with green arrows are located subparallel below the known mineralization and blue arrows indicate reflections dipping into the opposite direction of the known mineralization. 
https://doi.org/10.5194/se-2021-101

Preprint. Discussion started: 17 August 2021

(c) Author(s) 2021. CC BY 4.0 License.

\section{Interpretation and discussion}

The main mineralization including its surrounding host rock structures like the major crosscutting fault were successfully imaged, which is the basis for further structural interpretation. The reflectors related to the mineralization are clear and pronounced and appear to be highly reflective. They are partly intersecting with varying characteristics in lateral direction and in some parts, they exhibit a rather complex 3D shape. In order to verify the reliability of the image, we performed a detailed comparison of the imaged structures with the geological model of the known mineralization. The good agreement between the position of the known main mineralization and the position of the reflectors in our obtained seismic volume was already shown in Figure 7. Figure 9 shows a detailed view on the FVM image together with the current model of the second known mineralization (blue body) (M2). The imaged position, the dip and the general shape of the reflectors fit almost perfectly to the corresponding position of the known geological model of the ore bodies. Furthermore, the reflector corresponding to the main mineralization (blue body in Figure 9) is traceable at least $300 \mathrm{~m}$ further downward from the known downdip end of the mineralization. Additionally, the seismic image reveals a bowl-type shape (likely a tight fold) of this reflector in crossline direction (parallel to the main strike direction) which can be followed laterally even further upward beyond the known model of the mineralization (yellow ellipse in Figure 9a).
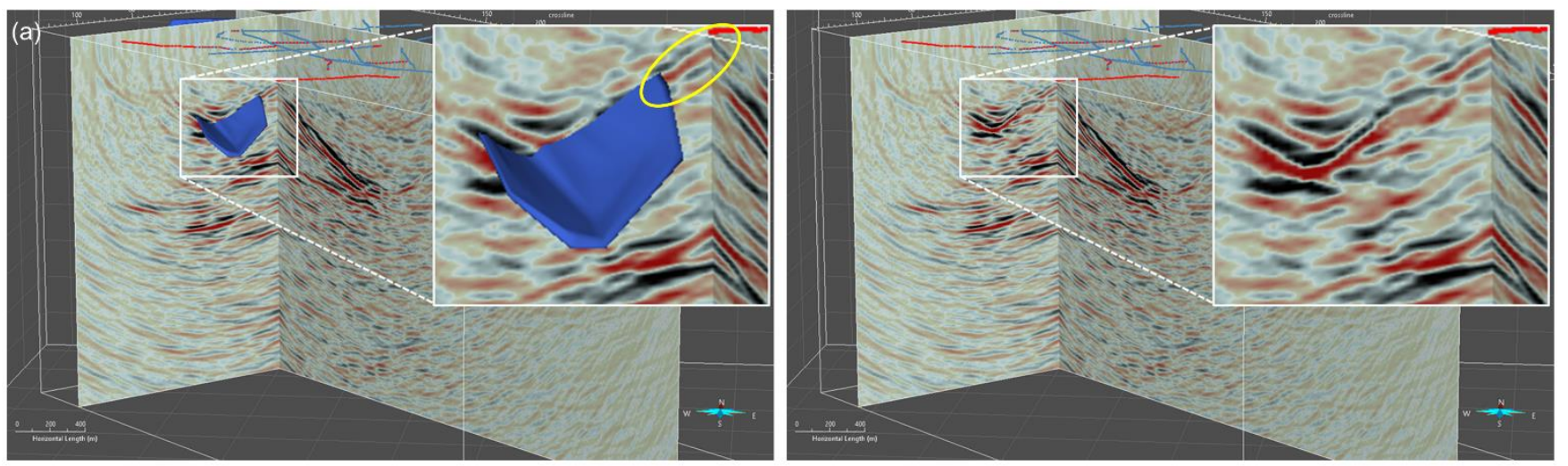

370 Figure 9: Perspective view with (a) and without (b) the model of the known mineralization (blue body). The zoomed inset shows a good agreement of the position, depth and shape of the known mineralization and the corresponding reflectors in the seismic image.

We tried to trace all imaged reflectors in the 3D FVM image cube and manually picked the horizons to verify, complement and extend the known structural model of the mineralization and its host rock structures. The reflectors were picked only when they showed coherent and strong amplitude over a certain distance and were clearly traceable within the 3D seismic image cube. Indirect structural indicators like phase offsets along the reflectors or positions where reflectors seemed to be truncated were not picked. Furthermore, partly reflective structures were not automatically connected but they were rather left as separate surfaces so that the interpretation of their possible connection was left as objective as possible. The picked horizons are shown in Figure 10. Figure 10a and $\mathrm{b}$ represent perspective views on the models of the known mineralization together with the picked horizons. The view direction is from South to North (Figure 10a) and from East to West (Figure 10b), respectively. The picked 
https://doi.org/10.5194/se-2021-101

Preprint. Discussion started: 17 August 2021

(c) Author(s) 2021. CC BY 4.0 License.

(c) (i)

horizons M1 and M2 are shown in red and blue in accordance to the known mineralization bodies, and the crosscutting reflector $\mathrm{C} 1$ is shown in gold. For the picked $\mathrm{C} 1$ reflector, the corresponding horizon extends downward to its lower end at a depth of approximately $1000 \mathrm{~m}$. It is illuminated by the source-receiver geometry mainly in the central part of the investigation area. It presumably continues further up-dip (to the southwest), but with the given acquisition geometry it is not possible to illuminate it further towards the surface. The same applies to the lower end of this reflector. It is possible that the structure may continue deeper but it is not illuminated by the acquisition geometry. However, an extrapolation of this horizon (in form of a mean plane for all picks, purple plane in Figure 10c) shows its possible continuation within the image cube. The surface outcrop of this extrapolated horizon would be located in the western part of the image cube with a strike direction almost north-south. Figure 10d shows where the mean plane would reach the surface and its relation to the known mapped surface geology. The surface location and strike direction of the mean plane fits perfectly to a mapped lineament in the geological map (yellow arrows in Figure 10d). Therefore, it is highly likely that this mapped fault and the imaged reflector refer to the same structure. As described above the two main reflectors M1 and M2 show the same location, dip angle and shape as the known mineralization. Beside this agreement, the reflectors show an about $300 \mathrm{~m}$ lateral and downward continuation of the previously known mineralization, meaning a potential continuation of the mineralized bodies and therefore additional resources. Assuming that the crossing reflector $\mathrm{C} 1$ is marking the lower end of the mineralization bodies, would allow to fill the gap

395 between $\mathrm{C} 1$ and M2, which means an even larger downward continuation for this reflector, than it is directly visible in the FVM image.

A comparison to the post-stack time migrated and time to depth converted result by Malehmir et al. (2021) shows a lot of similarities but also some differences. The main imaged reflectors (M1, M1 and C1, or F1 in Malehmir et al., 2021) are present in both results. The $\mathrm{C} 1$ reflector is much better imaged in the pre-stack depth image from FVM. Here it appears as a relatively sharp and continuous reflector, especially in the direct vicinity of the lower end of the M1 and M2 reflectors. In contrast, the PSTM image of this reflector is only piece-wise evident and less continuous, but it is imaged also in shallower depths. The reason for the better image here is presumably the opposite dip of the intersecting reflectors (C1 and M1, M2) which have to be adequately addressed during stacking in the post-stack approach and might have caused some problems. Whereas, the different dip directions are naturally handled by the pre-stack depth migration approach and such the reflectors are imaged properly. Furthermore, the sharp image of the FVM allows for a detailed interpretation of the visible reflectivity and allow to trace individual reflectors through the migrated volume. Such, we were able to map the M1 and M2 reflectors resulting in that fold shape seen in Figure 9. Finally, the application of pre-stack depth migration directly results in a depth image, rather than in a time image. For the latter, a post migration, time-to-depth conversion is needed in order to interpret the seismic image in

410 depth. This conversion often is done with a velocity, or a velocity function to best fit a-priori (e.g. borehole) information. The pre-stack depth image shown here is completely data-driven and nevertheless fits well to the a-priori information. This means that a high reliability of the resulting seismic image and especially the imaged depths and dips of the visible reflectors can be assumed. 
415 Potential for future works are the incorporation of a more detailed P-wave velocity model derived from e.g. full-waveforminversion (Singh et al., 2021 in prep.) for static corrections or even directly as part of a 3D migration velocity model. Furthermore, the acquired 3D data set could be used for a 3D Migration Velocity Analysis using focusing pre-stack depth migration techniques to generate common offset images, which then can be sorted into common image gathers depending not only on the offset, but also on the angles of illumination. Since the imaged structures are characterized by different strike directions and inclination angles, together with conflicting dip situations, more advanced investigations could be helpful. The already performed slowness calculation, which is needed for backpropagating the rays within FVM, could be used to distinguish between different emergent angles and directions for the reflected signals within the application of focusing 3D pre-stack depth migration variants. Furthermore, the obtained structures are currently analysed and interpreted together with other geophysical findings and geological data in order to obtain a comprehensive 3D model of the mineral deposit. The latter can then serve as a reliable basis for prospective modelling as well as estimates of its economic potential.
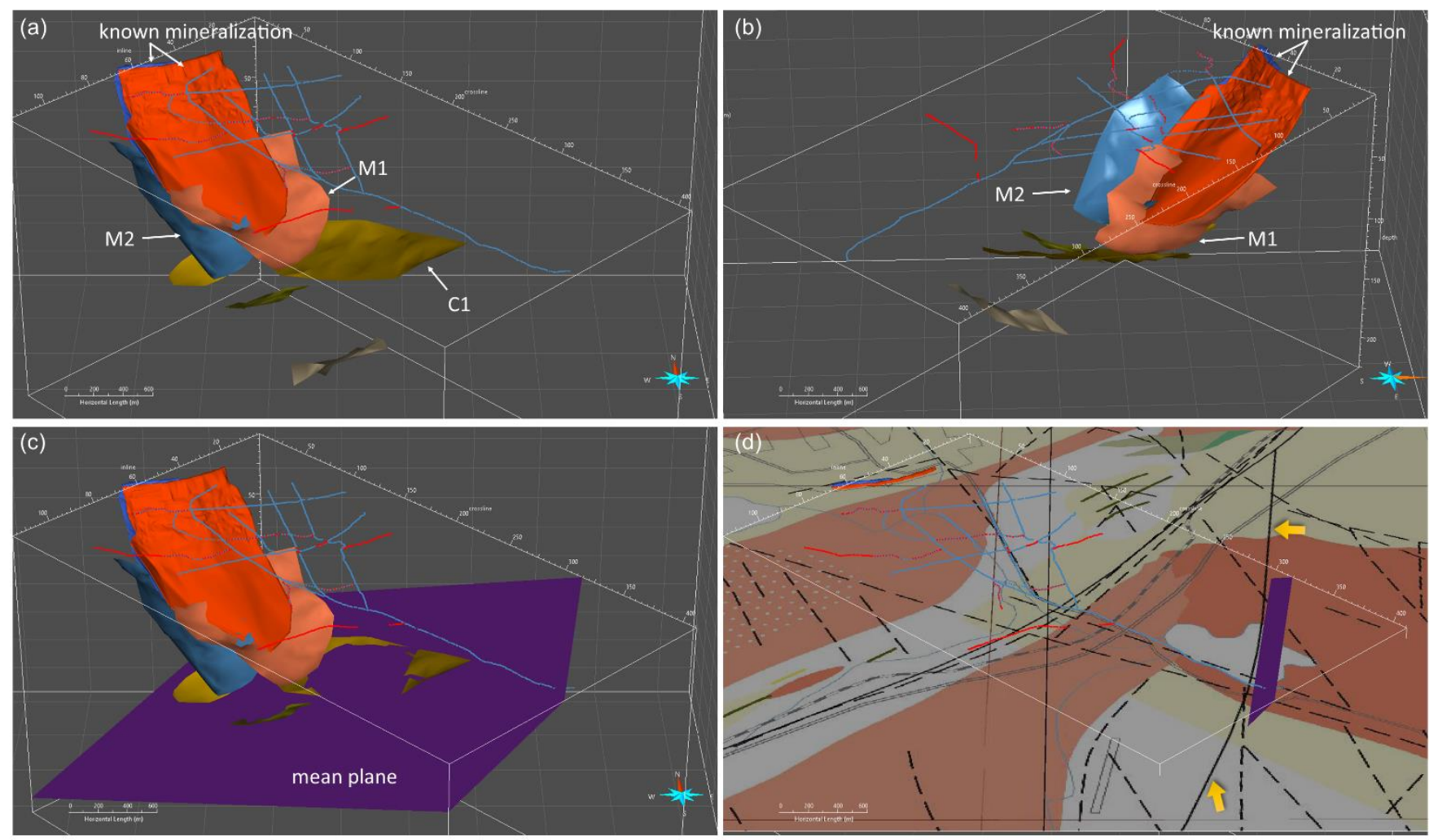

Figure 10: Interpretation of the identified and picked horizons: (a) and (b) show perspective views on the picked horizons and the model of the known mineralization. The crosscutting reflector $\mathrm{C} 1$ is extrapolated using a mean plane (purple plane (c)), which intersects with the surface at a mapped fault line (yellow arrows in d). 
https://doi.org/10.5194/se-2021-101

Preprint. Discussion started: 17 August 2021

(c) Author(s) 2021. CC BY 4.0 License.

(c) (i)

\section{Conclusions}

The acquired sparse 3D data set provides an excellent basis for the application of seismic processing and imaging techniques in the framework of mineral exploration in hardrock geological settings. Our workflow includes the application of a tailored pre-processing flow as well as the application of a 3D focusing seismic depth imaging technique (Fresnel Volume Migration). Both steps are accompanied by 3D first-arrival travel-time inversion to obtain static corrections within the processing flow, instead of handling statics shifts through the detailed velocity model incorporated in travel time calculation which would not be practical, as it requires very fine model discretisation. Such, the application of static corrections allows the usage of a simple 1D gradient model as migration velocity model. The latter results in a sharp image of the subsurface structures with a rather high accuracy in depth positioning and allows for a detailed interpretation.

440 The chosen processing approach delivered a high-quality 3D seismic cube with several distinct structural features that could not only be related to the known mineralization but also provide information of its possible extension in lateral direction as well as towards greater depths for the known mineralization in the study area.

\section{Acknowledgments}

445 We thank all colleagues, students and young professionals involved in the project Smart Exploration. A special thanks to all people involved in the field work of the 2019 survey and NIO for their support for planning and during the field campaign. The GOCAD Consortium and Paradigm are thanked for providing an academic license of GOCAD for 3D visualization and interpretation of the data. We acknowledge the usage of the Vibroseis truck of Technische Universität Bergakademie Freiberg, operated by the Institute of Geophysics and Geoinformatics and funded by the Deutsche Forschungsgemeinschaft (DFG) under

450 grant no. INST 267/127-1 FUGG, which was used as the seismic source in this survey. We also gratefully acknowledge the Halliburton Software Grant for the Technical University Bergakademie Freiberg, which enabled part of the data processing with their software package SeisSpace/ProMAX. The depth migrations were calculated with the help of the HPC cluster at TU Bergakademie Freiberg (DFG-grant INST 267/159-1 FUGG). IG PAS acknowledges the use of the Globe Claritas seismic processing package under the academic license from Petrosys Ltd and the TomoPlus software (Geotomo Inc.).

\section{Funding}

This research is part of the Smart Exploration project, which has received funding from the European Union's Horizon 2020 research and innovation programme under grant agreement No.775971. 
https://doi.org/10.5194/se-2021-101

Preprint. Discussion started: 17 August 2021

(c) Author(s) 2021. CC BY 4.0 License.

(c) (i)

\section{Data availability}

The presented data is available by contacting the corresponding author.

\section{Author contributions}

AM and PM designed the survey. AM, MaM, SB, LS, EB and FH contributed to the data acquisition. MiM performed the signal processing and calculated the static corrections. FH wrote the main content of this manuscript, applied KPSDM and FVM and created the 3D interpretation of the seismic data. All authors contributed to the interpretation and discussions of the results and to discussions during the processing of the data.

\section{Competing interests}

The authors declare that they have no conflict of interest.

\section{References}

Bellefleur, G., Schetselaar, E., White, D., Miah, K., Dueck, P.: 3D seismic imaging of the Lalor volcanogenic massive sulphide deposit, Manitoba, Canada, Geophysical Prospecting, 63, 813-832, doi: 10.1111/1365-2478.12236, 2015.

Buske, S., Gutjahr, S. and Sick, C.: Fresnel volume migration of single-component seismic data. Geophysics, 74, WCA47WCA55, 10.1190/1.3223187, 2009.

Buske, S.: Three-dimensional pre-stack Kirchhoff migration of deep seismic reflection data. Geophysical Journal International,

Bräunig, L., Buske, S., Malehmir, A., Bäckström, E., Schön, M., and Marsden, P.: Seismic depth imaging of iron-oxide deposits and their host rocks in the Ludvika mining area of central Sweden, Geophysical Prospecting, 68, 24-43, doi: 10.1111/1365-2478.12836, 2020.

Cheraghi, S., Malehmir, A., Bellefleur, G.: 3D imaging challenges in steeply dipping mining structures: New lights on acquisition geometry and processing from the Brunswick no. 6 seismic data, Canada, Geophysics, 77, WC109-WC122, doi: 10.1190/geo2011-0475.1, 2012. 
https://doi.org/10.5194/se-2021-101

Preprint. Discussion started: 17 August 2021

(c) Author(s) 2021. CC BY 4.0 License.

(c) (i)

485 Cyz, M. C., and M. M. Malinowski: Comparison of refraction and diving wave tomography statics solution along a regional seismic profile in SE Poland. In 75th EAGE Conference \& Exhibition incorporating SPE EUROPEC 2013, pp. cp-348. European Association of Geoscientists \& Engineers, 2013.

Hampson, D., and B. Russell: First-break interpretation using generalized linear inversion, Journal of the Canadian Society of 490 Exploration Geophysicists, 20, 40-54, 1984.

Heinonen, S., Malinowski, M., Hloušek, F., Gislason, G., Buske, S., Koivisto, E. and Wojdyla, M., Cost-effective seismic exploration: 2D reflection imaging at the Kylylahti massive sulfide deposit, Finland. Minerals, 9(5), 263, doi.org/10.3390/min9050263, 2019.

495

Hloušek, F. and Buske, S., Fresnel Volume Migration of the ISO89-3D data set. Geophysical Journal International, doi:10.1093/gji/ggw336, 2016.

Hloušek, F., Hellwig, O., Buske, S., Improved structural characterization of the Earth's Crust at the German Continental Deep 500 Drilling Site (KTB) using advanced seismic imaging techniques. Journal of Geophysical Research (Solid Earth), 10.1002/2015JB012330, 2015.

Jones, I. F., Velocities, Imaging and Waveform Inversion: The Evolution of Characterising the Earth's Subsurface. EAGE Publications, 2018.

Lüth, S., Buske, S., Goertz, A. and Giese, R., Fresnel-volume migration of multicomponent data. Geophysics, 70(6): 121-129, 2005.

Malehmir, A., Durrheim, R., Bellefleur, G., Urosevic, M., Juhlin, C., White, D. J., Milkereit, B. and Campbell, G: Seismic 510 methods in mineral exploration and mine planning: A general overview of past and present case histories and a look into the future. Geophysics, 77(3): WC173-WC190, 2012.

Malehmir, A., G. Maries, E. Bäckström, M. Schön and P. Marsden: Developing cost-effective seismic mineral exploration methods using a landstreamer and a drophammer. Scientific Reports, 7(1), 2017.

Malehmir, A., Markovic, M., Marsden, P., Gil, A., Buske, S., Sito, L., Bäckström, E., Sadeghi, M., and Luth, S.: Sparse 3D reflection seismic survey for deep-targeting iron-oxide deposits and their host rocks, Ludvika Mines-Sweden, Solid Earth, 12, 483-502, doi.org/10.5194/se-12-483-2021, 2021. 
https://doi.org/10.5194/se-2021-101

Preprint. Discussion started: 17 August 2021

(c) Author(s) 2021. CC BY 4.0 License.

(c) (i)

520 Maries, G., Malehmir, A., Bäckström, E., Schön, M., and Marsden, P.: Downhole physical property logging for iron-oxide exploration, rock quality, and mining: An example from central Sweden, Ore Geology Reviews, 90, 1-13, 2017

Maries, G., Malehmir, A., and Marsden, P.: Cross-profile seismic data acquisition, imaging and modeling of iron-oxide deposits: a case study from Blötberget, south central Sweden, Geophysics, https://doi.org/10.1190/geo2020-0173.1, 2020.

525 Markovic, M., Maries, G., Malehmir, A., von Ketelholdt, J., Bäckström, E., Schön, M., and Marsden, P.: Deep reflection seismic imaging of iron-oxide deposits in the Ludvika mining area of central Sweden, Geophysical Prospecting, 68, 7-23, 2020.

Milkereit, B., Eaton, D., Wu, J., Perron, G., Salisbury, M. H., Berrer, E. K., \& Morrison, G.: Seismic imaging of massive 530 sulfide deposits; Part II, Reflection seismic profiling. Economic Geology, 91(5), 829-834, 1996.

Neidell, N. S. and Taner, M. T.: Semblance and other coherency measures for multichannel data. Geophsics, 36, 482-497, 1971

535 Schneider W.A. Integral formulation for migration in two and three dimensions. Geophysics 43, 49-76, 1978.

Singh, B., Malinowski, M., Hloušek, F., Koivisto, E., Heinonen, S., Hellwig, O., Buske, S., Chamarczuk, M. and Juurela, S., Sparse 3D seismic imaging in the Kylylahti mine area, Eastern Finland: comparison of time versus depth approach. Minerals, 9(5), doi.org/10.3390/min9050305305, 2019.

540

Singh, B., Malinowski, M., Górszczyk, A., Malehmir, A., Buske, S., Sito, Ł. and Marsden P., 3D high-resolution seismic imaging of the iron-oxide deposits in Ludvika (Sweden) using full-waveform inversion and reverse-time migration, Solid Earth, 2021, in prep.

545 Riedel, M., Dutsch, C. Alexandrakis, C., Dini, I., Ciuffi, S., Buske, S., Seismic depth imaging of a geothermal system in southern Tuscany. Geophysical Prospecting, 10.1111/1365-2478.12254, 2015.

Urosevic, M., Bhat, G., and Grochau, M. H., Targeting nickel sulfide deposits from 3D seismicreflection data at Kambalda, Australia, Geophysics, 77, WC123-WC132, doi: /10.1190/geo2011-0514.1, 2012.

Zhang J. and Toksöz M.N.: Nonlinear refraction traveltime tomography. Geophysics 63, 1726-1737, 1998 